\title{
Performance Evaluation the Turbidity Removal Efficiency of AL-Muthana Water Treatment Plant
}

\author{
Mohammad Abd Nasier \\ M.Sc. student \\ College of Engineering \\ University of Baghdad \\ Baghdad-Iraq \\ mohammasnasier0@gmail.com
}

\author{
Dr. Khalid Adel Abdulrazzaq \\ Assistant Professor \\ College of Engineering \\ University of Baghdad \\ Baghdad-Iraq \\ aleoubaidy@coeng.uobaghdad.edu.iq
}

\begin{abstract}
Turbidity is a visual property of water that expresses the amount of suspended substances in the water. Its presence in quantities more significant than the permissible limit makes the water undrinkable and reduces the effectiveness of disinfectants in treating pathogens. On this basis, turbidity is used as a basic indicator for measuring water quality. This study aims to evaluate the removal efficiency of AL- Muthanna WTP. Water turbidity was used as a basic parameter in the evaluation, using performance improvement evaluation and data from previous years (2016 to 2020). The average raw water turbidity was 26.7 NTU, with a minimum of 14 NTU, with a maximum of 48 NTU. Water turbidity value for $95 \%$ of settling daily reading data was (13.7) NTU which is larger than the goal value (10) NTU, which achieves (51.2) \% of the optimum goal. In comparison, the water turbidity value for $95 \%$ of daily reading data of water filtered was (6.90) NTU which is larger than the goal value (5) NTU, which achieves (68.8) \% of the optimum goal. The removal efficiency for previous years (2016 to 2020) was $(78.5,76,73.5,72,68) \%$, respectively, within acceptable limits.
\end{abstract}

Keywords: Performance, Evaluation, Removal efficiency, Turbidity

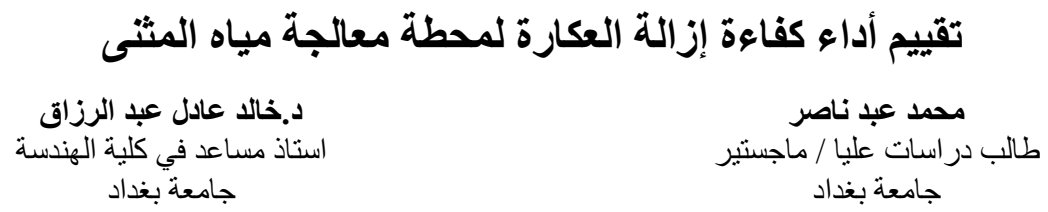

الخلاصة

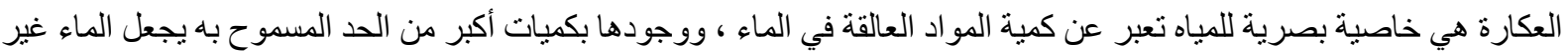

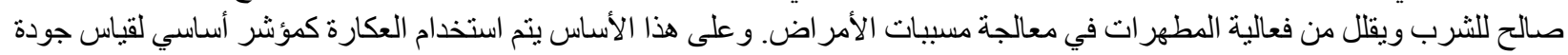

*Corresponding author

Peer review under the responsibility of University of Baghdad.

https://doi.org/10.31026/j.eng.2022.03.01

2520-3339 () 2022 University of Baghdad. Production and hosting by Journal of Engineering.

This is an open access article under the CC BY4 license http://creativecommons.org/licenses/by/4.0/).

Article received: $21 / 11 / 2021$

Article accepted: $23 / 12 / 2021$

Article published:1/3/2022 


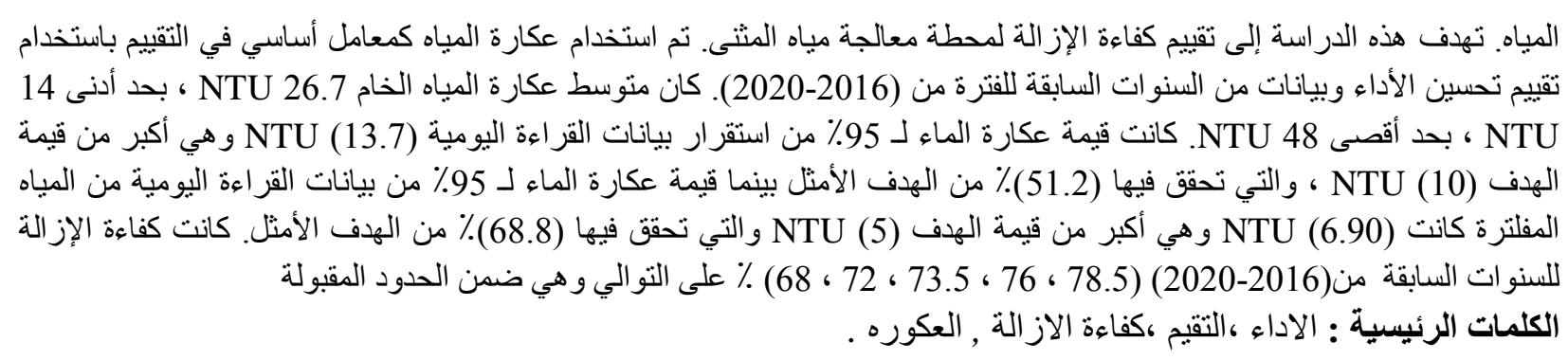

\section{INTRODUCTION}

Water is an essential component of life and an important factor in achieving human and economic development. Water scarcity is a major obstacle to long-term development efforts. The consistent population growth and the expected effects of climate change in the region, which has become a tangible reality, contribute to increasing pressure on limited water resources and reconsidering water management methods, which requires review and evaluation of performance (Bârjoveanu et al., 2019). As the international authority on public health and water quality, the World Health Organization promotes global efforts to prevent the spread of waterborne diseases, advises governments on developing health goals and systems, and develops drinking water treatment methods based on FAO's health performance standards.

In addition to evaluating water treatment technologies and urging governments to provide safe, pathogen-free water, the goal is to strengthen national policies, regulations, and control mechanisms to support appropriate targeting and continued use of these products (Hassan and Mahmood, 2018). A comprehensive performance evaluation (CPE), which is a thorough review and analysis of a water treatment plant's performance-based capabilities as well as the associated administrative, operational, and maintenance practices, was one of the numerous methods used to evaluate the water treatment plant. (Hamada M. Mahmoud et al., 2016). It is carried out to identify factors affecting a plant's performance. The comprehensive performance evaluation is an integrated program that serves as an effective tool for understanding the operational problems and difficulties that drinking water treatment plants face, as well as knowing the efficiency of the work of the units of those plants based on the chemical, physical, and biological characteristics of raw and treated water to determine the quality of pollutants removed (Chang et al., 2007).

Since most treatment plants operate conventionally, physical parameters, especially water turbidity, are most commonly used to evaluate the operating performance of water plants and main treatment units in terms of removal efficiency and evaluation of the quality of the water produced (Issa, 2017). Most developed countries have developed an integrated program for reviewing and evaluating drinking water plants in order to identify the problems and obstacles that prevent the achievement of economic feasibility and the goals that these stations were established on, as well as to provide appropriate solutions to advance the reality of the treatment process(Absar Ahmed Khan and M.Tech., 2018). The target of this research assessment is the performance removal efficiency of AL-Muthanna WTP based on turbidity as the main parameter. 


\section{Methodology and method of work}

2.1. Historical data for raw and product water from (2016 to 2020) were used to calculate the annual removal efficiency.

2.2. Data of raw water turbidity were collected for roughly eleven months, beginning in January 2021 to the end of November 2021. Samples were modeled during basic treatment methods (raw water, coagulation, flocculation, sedimentation, and filtration), and this data was entered into the optimization assessment software (OAS), which is a program developed by the US Environmental Protection Agency that aims to examine the performance. This data was analyzed through tables and graphs. When turbidity of raw water is $\leq 10$ NTU for $95 \%$ of sample readings, the sedimentation basin performance approach shows the water turbidity settled $\leq 2.0 \mathrm{NTU}$ for $95 \%$ of time. In terms of filtered water performance, it is based on achieving 0.1 NTU in $95 \%$ of the models under test. The maximum turbidity values recorded daily for eleven months were used to provide a clear picture of the seasonal variation in the treatment plant's operation. (Choi et al., 2002)

\subsection{Optimization assessment software (OAS)}

This program monitors the performance of the treatment plant using the data entered daily in order to achieve optimal performance by following steps:

I. Entering the maximum daily turbidity values for the raw water source and the effluent water from the sedimentation and filtration units in (Data Entry past sheet). Then, clicking on Transfer the data to the database in the green box.

II. After previse, step traveling to Data Entry values sheet then Fill the fields in the table which includes (plant name, Max. settled water turbidity goal $\leq 10 \mathrm{NTU}$, turbidity of filtered water optimization goal $\leq 0.1 \mathrm{NTU}$ and turbidity of filtered water regulation $\leq 5 \mathrm{NTU}$ ), when yellow values appear in the Data Entry values mean that it is outside the limits of achieving the optimum target value, click UPDATE the report to travel to the summary of the results in tables and figure found.

III. The OAS also includes a number of other worksheets that display performance data graphically. The majority of these are trend graphs of individual treatment unit performance. 


\section{Result and discussion}

\subsection{Turbidity Evaluation}

Table 1. listed the statistical turbidity values of raw, sedimentary, and filtered water from the beginning of January to the end of December 2021 compared to World Health Organization specifications. The average turbidity of raw water of the AL-Muthana water treatment plant was recorded at 26.7 NTU with a minimum value of 14 NTU and a maximum of 48 NTU. The highest turbidity levels were recorded during August, September, and October. The reason for the high turbidity of the raw water is the increased flow of water entering the river as well as the river dredging work done by the farmers in preparation for the planting season. Agricultural activities increase water turbidity during the dry season (Ojok, Wasswa, and Ntambi, 2017). The table also listed that the turbidity of the water was 13.7 NTU for $95 \%$ of the daily sediment readings, which is higher than the target to be reached $10 \mathrm{NTU}$, so the percentage of the time that the target was met $51 \%$. The table also explained that the turbidity of filter water was 6.90 NTU for $95 \%$ of daily readings, achieving $68 \%$ of the target standard, and show that $32 \%$ of daily filtered water was greater than the standard limit of 5 NTU. Fig. 1. and 2. represents the daily variation of turbidity in raw water, sediment water, and filter water over the study year. It failed to meet the optimized goal of $0.1 \mathrm{NTU}$ for the $95 \%$ of daily filter water readings. Due to the highest values are not provided for each filter, the results may obscure the effect of damaged lower drains for an individual filter or a malfunction of the filter rate control valves. Therefore, the profile gives a general idea of the performance of all filters as one unit. The low removal rates in sand filters are caused by important factors in which is a clear variation in the turbidity of the water reaching the filters as a result of the low efficiency of sedimentation basins, as well as a lack of periodic maintenance of the filters, particularly during times of increased demand. The efficiency removal of sand filters in a drinking water treatment plant is greatly affected by variations in the amount of water turbidity and the time required to perform the backwashing process, as well as the skill of workers in these units, which occurs when increased demand negatively affects the product's water quality (García-Ávila et al., 2020). 
Table1. OAS Summary Statistics.

\begin{tabular}{|c|c|c|c|c|c|c|c|}
\hline $\begin{array}{c}\text { ANNUAL } \\
\text { DATA }\end{array}$ & Avg. & Min & Max & RSQ & $95 \%$ & Opt. Goal & Reg. \\
\hline & NTU & NTU & NTU & & NTU & $\%$ Values & $\begin{array}{c}\% \\
\text { Values }\end{array}$ \\
\hline $\begin{array}{c}\text { Raw } \\
\text { Turbidity }\end{array}$ & 26.7 & 14.0 & 48.0 & $\mathrm{n} / \mathrm{a}$ & 40.0 & $\mathrm{n} / \mathrm{a}$ & $n / a$ \\
\hline $\begin{array}{c}\text { Max. Settled } \\
\text { Turbidity }\end{array}$ & 10.1 & 5.3 & 15.8 & 0.86 & 13.7 & 51.2 & $\mathrm{n} / \mathrm{a}$ \\
\hline $\begin{array}{c}\text { Combined } \\
\text { Filtered } \\
\text { Turbidity }\end{array}$ & 4.48 & 2.00 & 8.90 & 0.73 & 6.90 & \#N/A & 68.8 \\
\hline
\end{tabular}

RSQ $=$ Correlation Coefficient for two selected data-sets $(>0.25$ suggests correlation) 95percent $=95$ th percentile value for data-set. Reg. $=$ Percent of values in data-set that is less than or equal to the regulated turbidity requirement

In general, the turbidity evaluation shows that about $48.8 \%$ of water turbidity effluent from the sedimentation unit exceeded the target limit (10NTU), which was negatively affected the filtration process. In contrast, the filtration process was relatively satisfactory in which sometimes the consumer was provided with water with turbidity higher than the standard limit (5) NTU. 


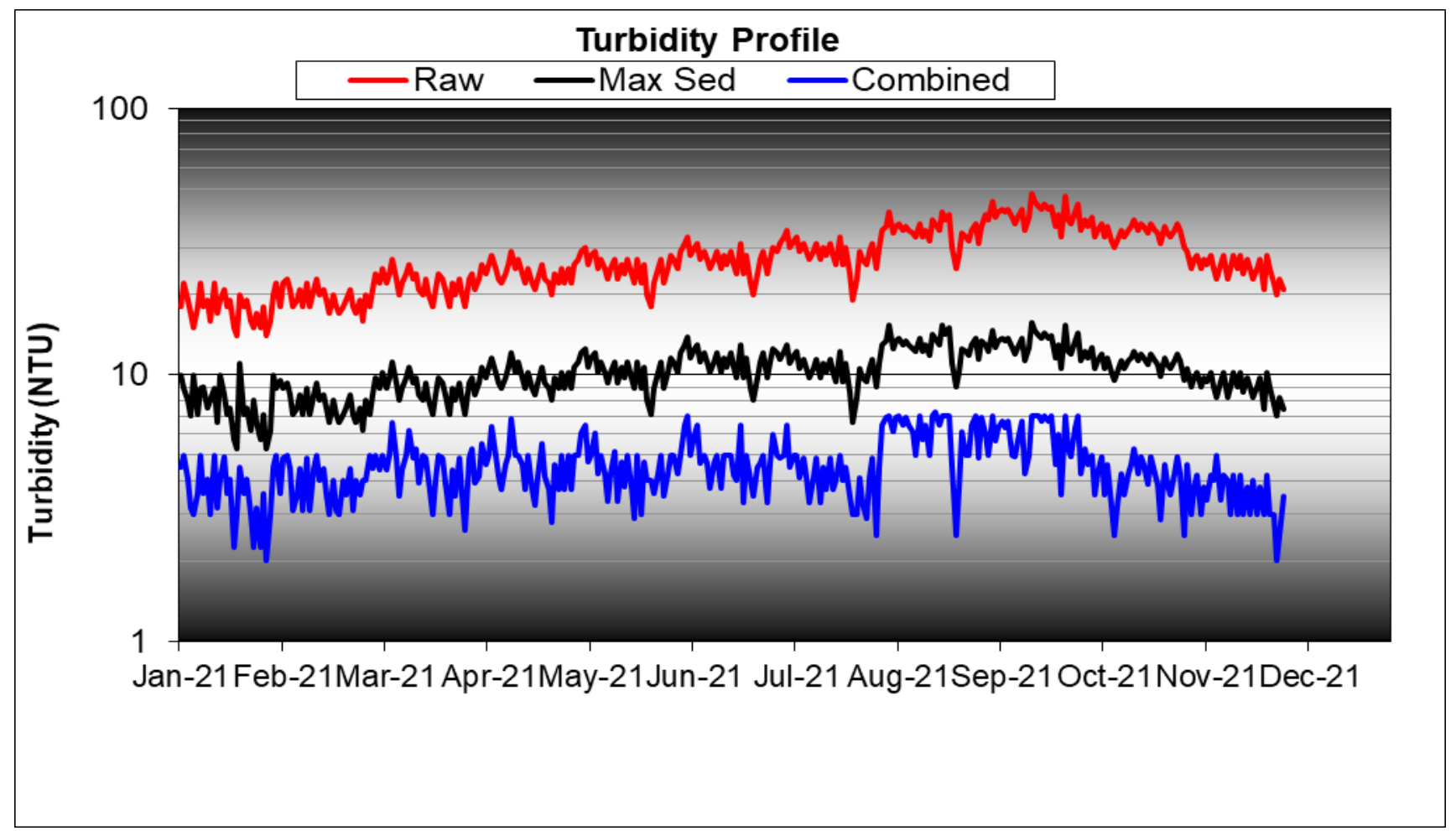

Figure 1. OAS turbidity data profile.

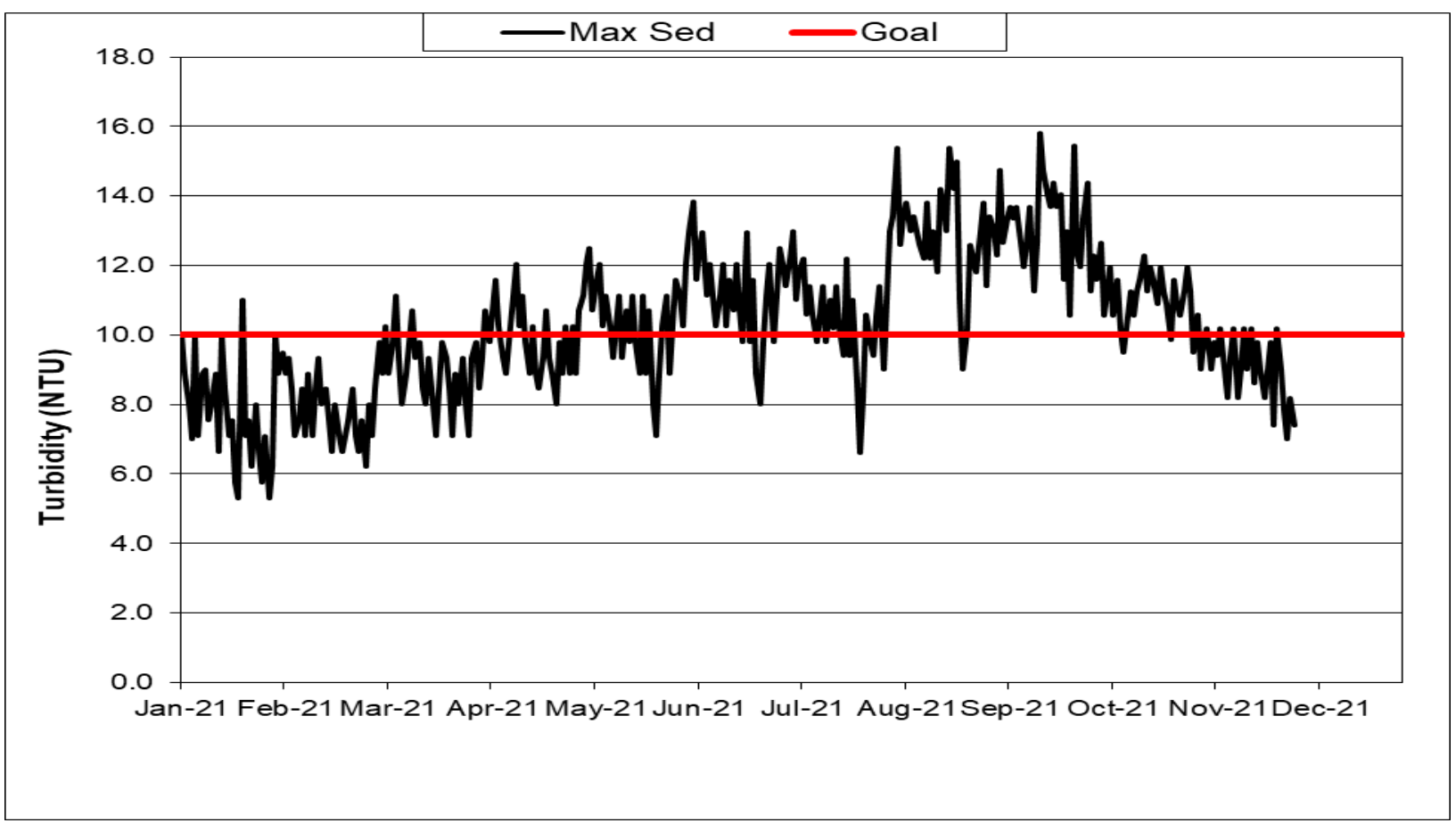

Figure 2. Maximum variation turbidity trend. 


\subsection{Removal efficiency evaluation}

Fig. 3 to Fig. 6 listed the AL-Muthana water treatment plant's monthly and annual turbidity removal from 2016 to 2020 as $(78.5,76,73.5,72$, and 68), respectively. The figures also show that the removal rate was reduced, but it was still within acceptable limits. Variation in raw water turbidity affects the efficiency level of drinking water treatment plants, so the water must be tested and monitored regularly. The water treatment plant should be modified to produce water that is at least close to the required quality. The water treatment plant is designed to handle various types of raw water. When there are large variations in water quality, the equipment may not fit at all (Kiggundu et al., 2016). Maintenance of the water treatment is also an affecting factor affecting the plant's process because the seasonal variation in raw water (during summer and rainy) affects the process, and other factors will change quality output water (Mahmood and Al-Musawi, 2020). So, proper maintenance is essential to ensure that the system is adequately maintained to reach the desired result. The maintenance of water treatment includes monitoring agreement, daily data about the process of the plant, and the plant productivity observation (Omran, 2011).

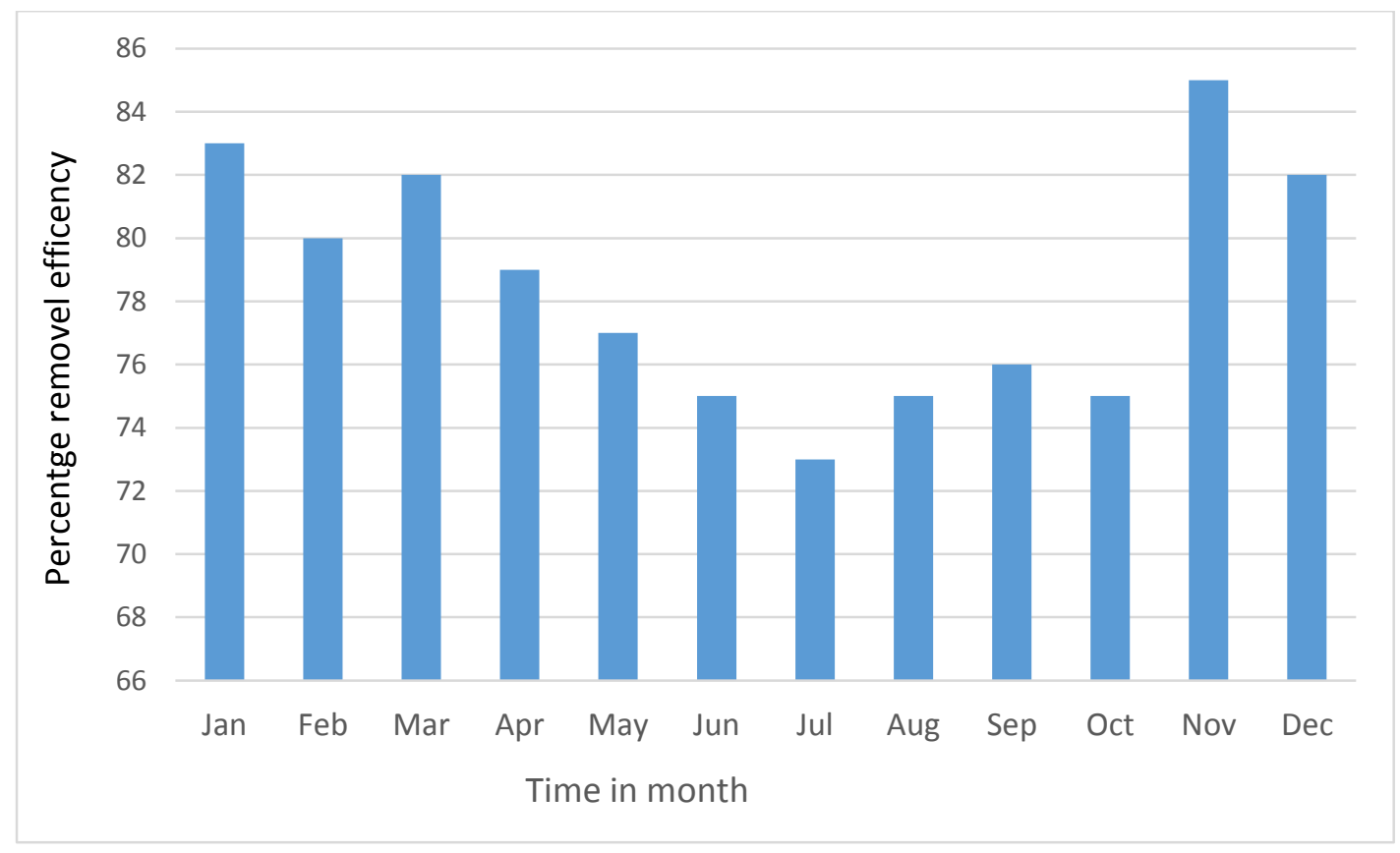

Figure 3. Turbidity removal efficiency (2016). 


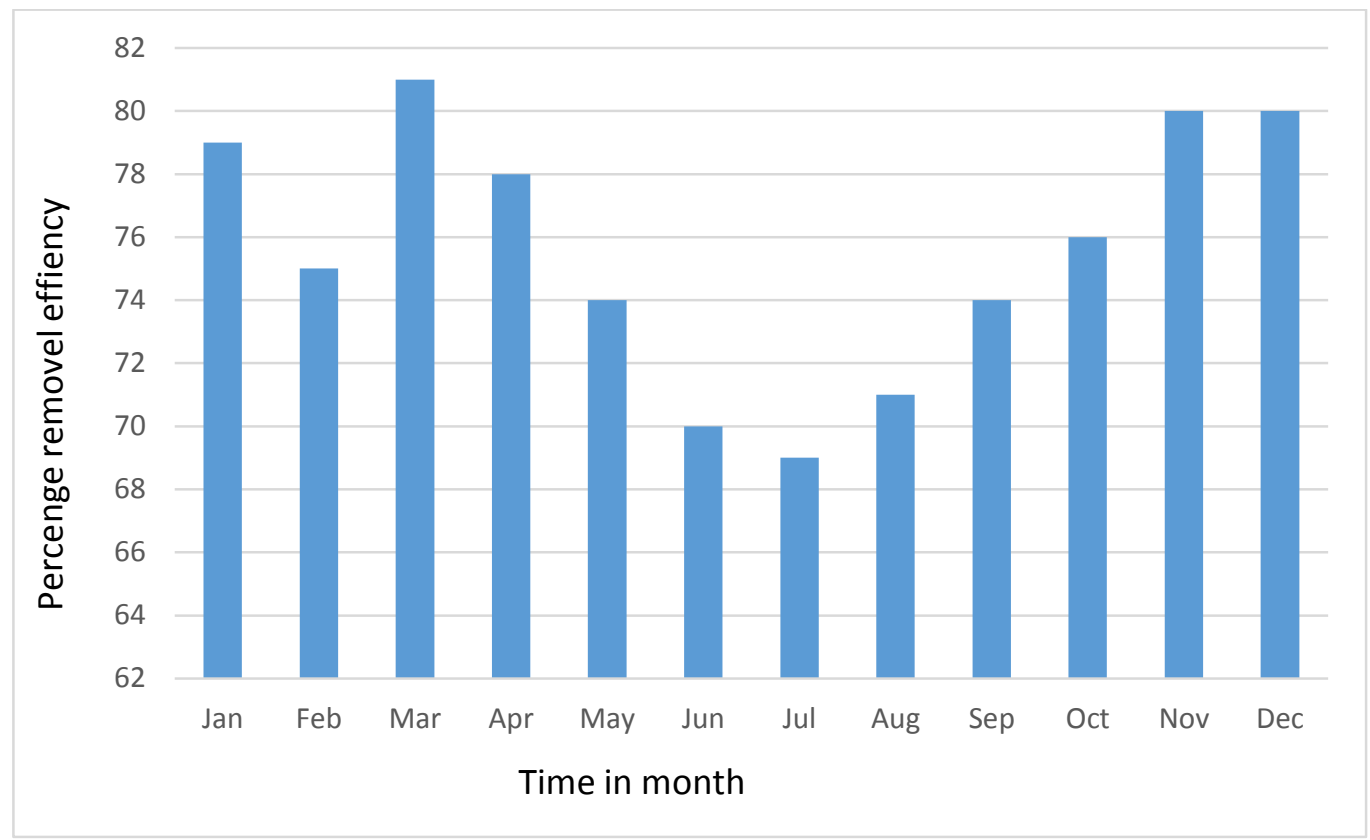

Figure 4. Turbidity removal efficiency (2017).

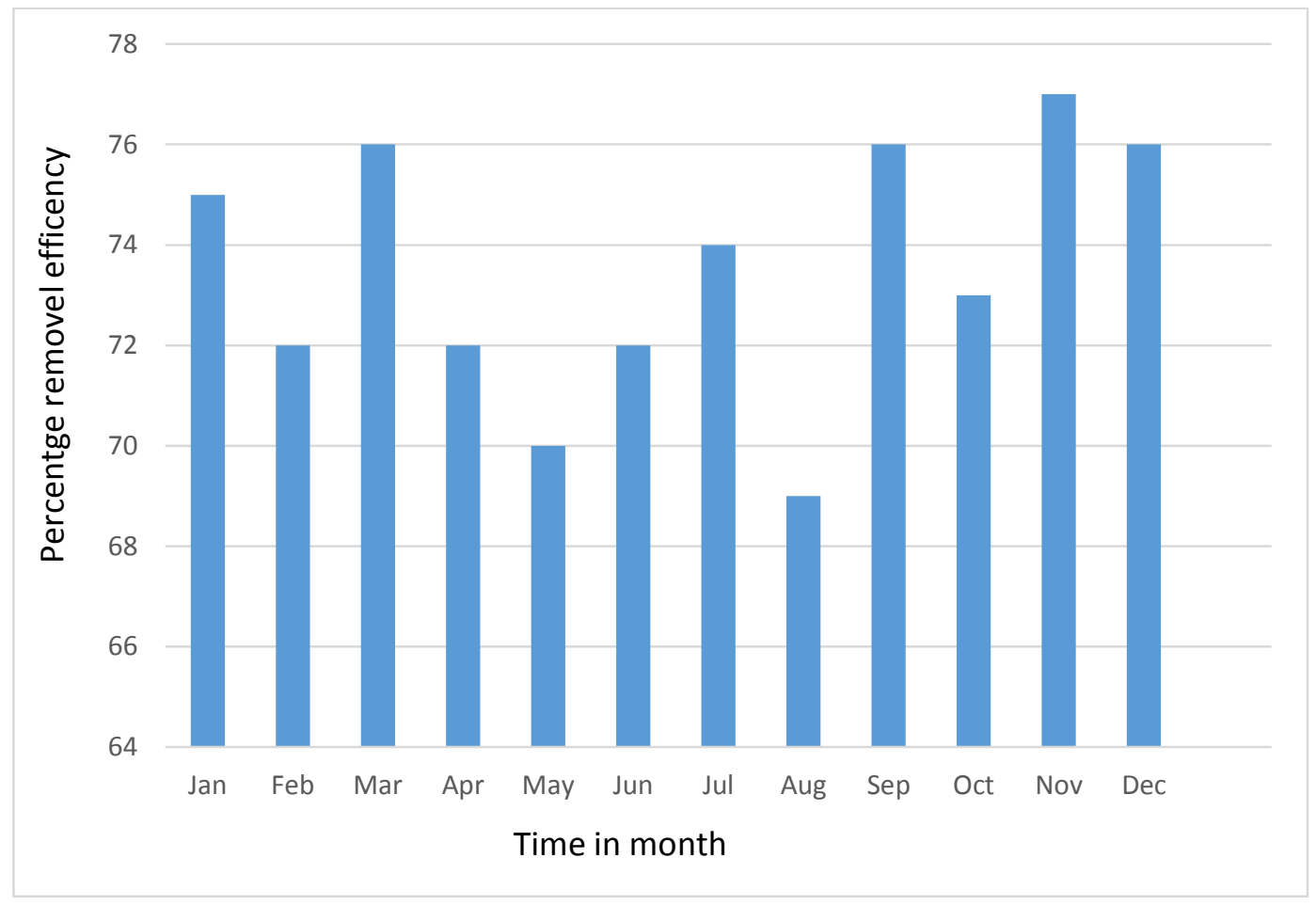

Figure 5. Turbidity removal efficiency (2018). 


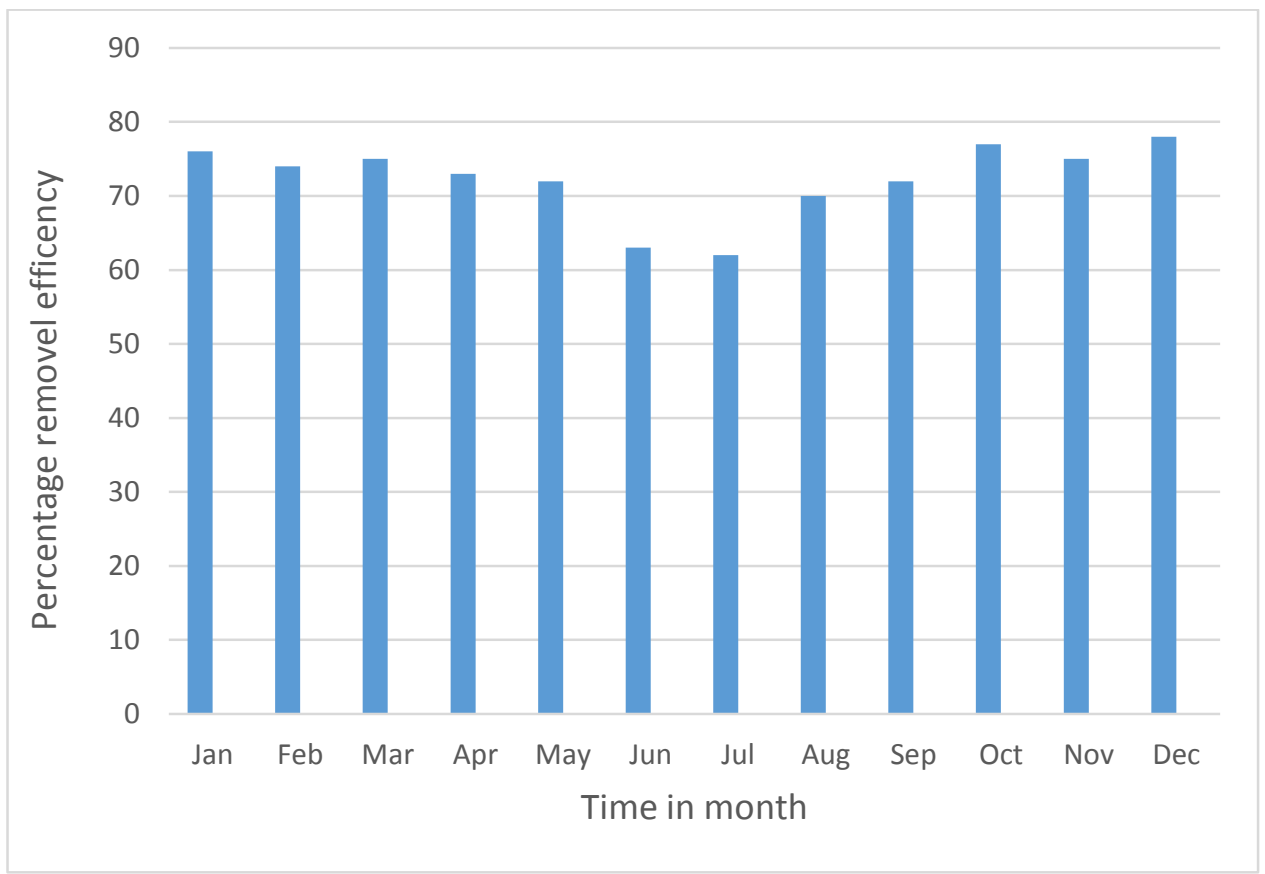

Figure 6. Turbidity removal efficiency (2019).

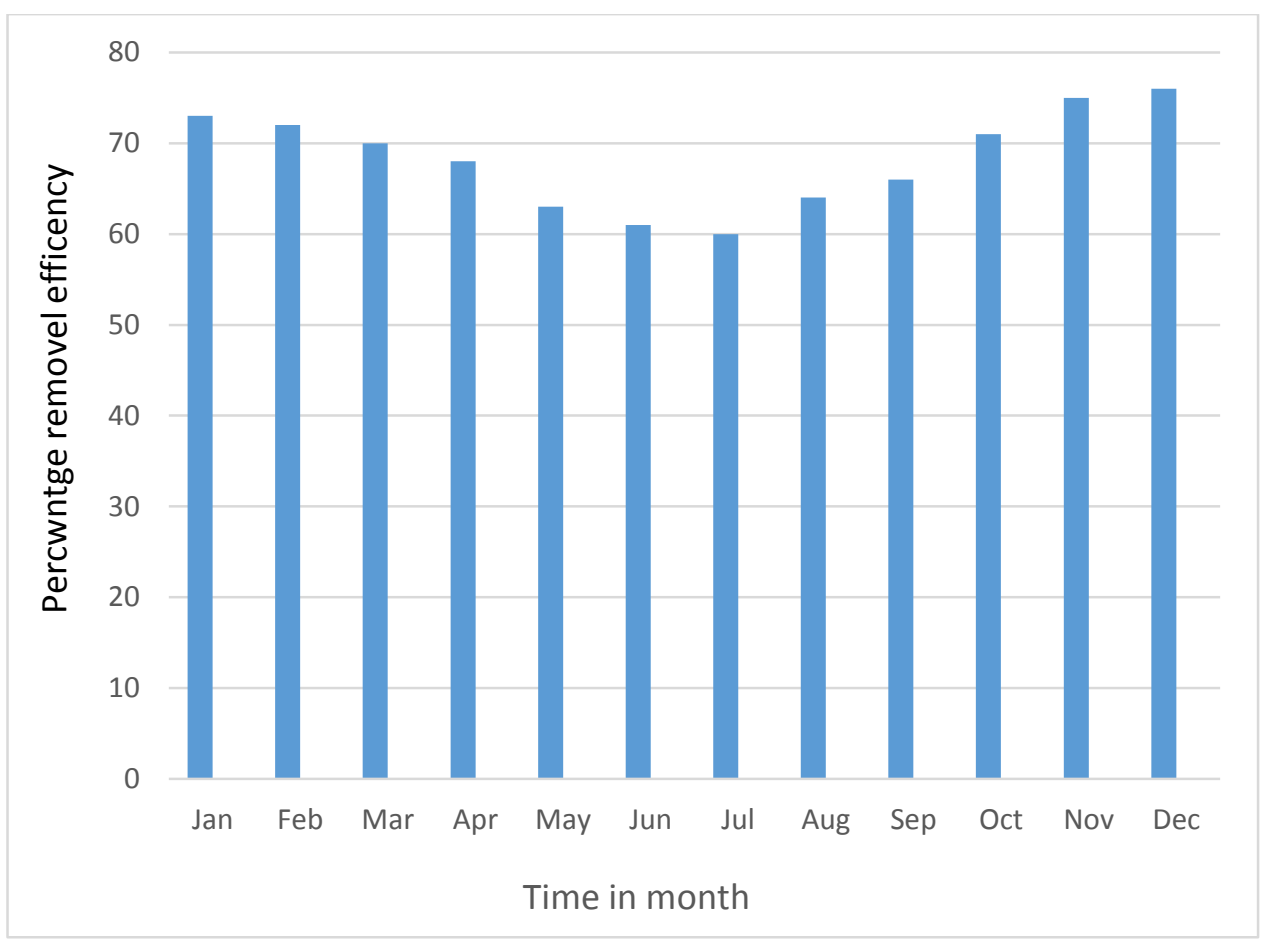

Figure 7. Turbidity removal efficiency (2020). 


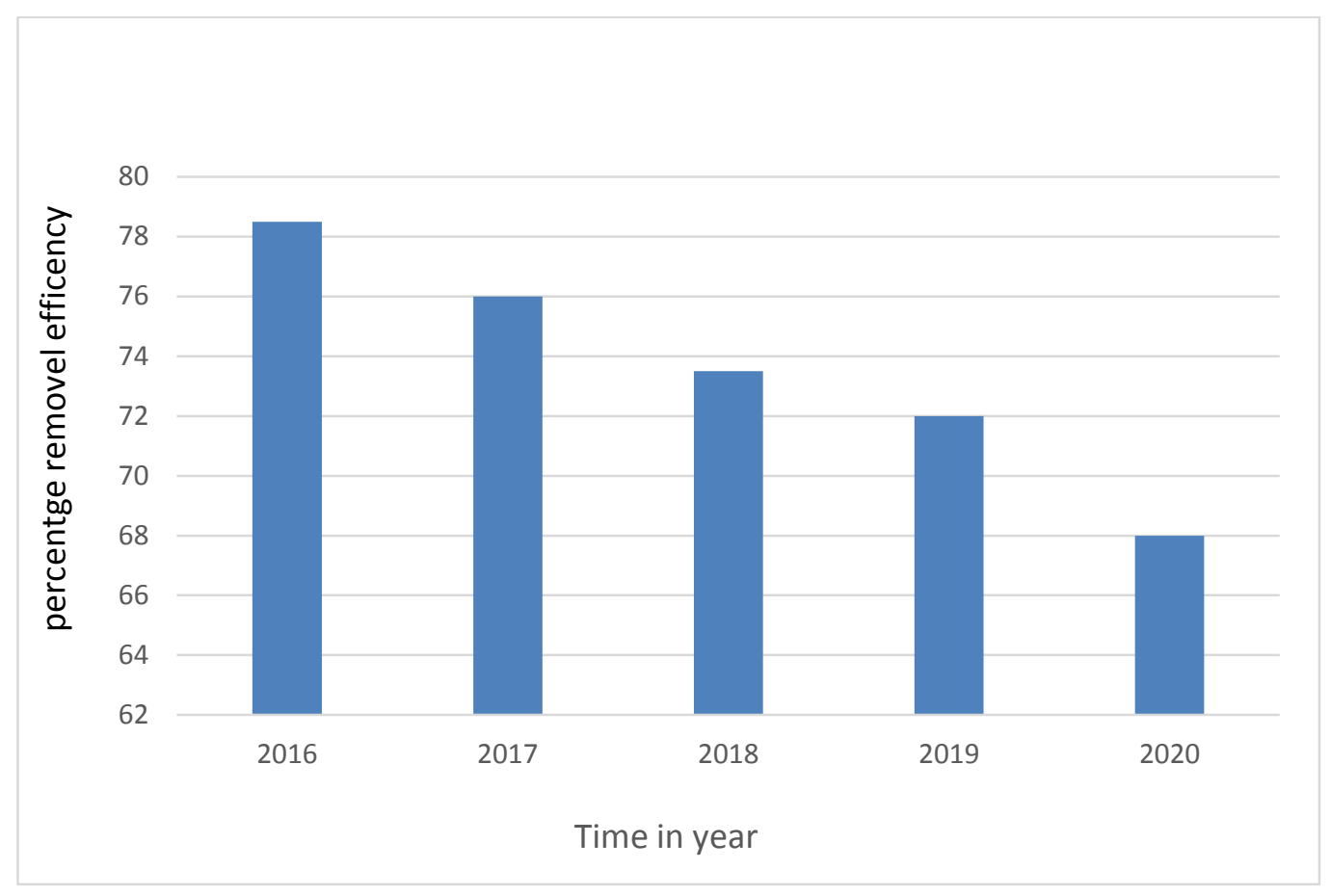

Figure 8. Annual Removal efficiency (2016-2020).

The reduction in monthly removal efficiency appears clearly during the summer season due to increased water demand resulting from high consumption. In addition, the dose of the coagulant was added randomly without conducting Jar-test to ensure the appropriate doses to achieve the best removal. Although the annual removal rate remains within acceptable limits, it is steadily declining, which was $13 \%$ during the period (2016 to 2020). This was due to various factors, including a lack of basic knowledge of water treatment among the majority of workers in these stations, insufficient daily monitoring of water quality and operating conditions, and a lack of financial allocations that do not meet the needs of maintenance and operation. This all agreed with the findings of a study conducted by (Abd Nasier and Abdulrazzaq, 2021).

\section{CONCLUSIONS}

AL-Muthana is a conventional water treatment plant in which turbidity removal is an important target, and the main conclusions are listed below:

I. The average turbidity of raw water of the AL-Muthana water treatment plant was recorded at 26.7 NTU with a minimum value of 14 NTU, and the maximum 48 NTU during August, September, and October, the highest turbidity levels were recorded. 
II. Water settled turbidity was 13.7 NTU for $95 \%$ of the daily sediment readings, which is higher than the target to be reached 10 NTU, so the percentage of the time that the target was met at $51 \%$. In comparison, the turbidity of filter water was 6.90 NTU for $95 \%$ of daily readings, achieving $68 \%$ of the target standard, and $32 \%$ of daily filtered water was greater than the standard limit of 5 NTU, which failed to meet the optimize goal of $0.1 \mathrm{NTU}$ for the $95 \%$ of daily filter water readings.

III. The OAS assists who was in charge of operating and supervising water treatment plants in analyzing collected turbidity data in order to determine performance indicators in relation to improvement goals and to identify potential factors limiting plant performance.

IV. Previous years' removal turbidity rates (2016 to 2020) were within acceptable limits, with a value of $(78.5,76,73.5,72$, and 68$)$ percent. However, the decrease in removal performance indicates the presence of operational issues that must be searched for and treated to ensure that the efficiency does not fall below the allowable limits.

V. In light of the results obtained, the turbidity removal efficiency of AL- Muthanna WTP remains satisfactory.

\section{RECOMMENDATIONS}

This study was completed in a short amount of time and with limited resources. Further research should be carried out to enhance and improve the removal efficiency based on the findings, and the following recommendations would be made:

I. To ensure a better operation of AL- Muthanna WTP, the administration should work to involve workers in development courses in operation and maintenance.

II. The variation in raw water quality should be monitored, and a Jar-test should be performed to obtain the appropriate coagulant doses and avoid adding coagulants at random. 


\section{REFERENCES}

- Abbas, Sabreen Hayder, Basim Hussein Khudair, and Mahdi Shanshal Jaafar. 2019. River Water Salinity Impact on Drinking Water Treatment Plant Performance Using Artificial Neural Network, Journal of Engineering 25(8):149-59, DOI: 10.31026/j.eng.2019.08.10.

- Absar Ahmed Khan1, Syed Khursheed Ahmad2, and 1M.Tech. 2018. PERFORMANCE EVALUATION OF WATER TREATMENT PLANT AT NANGLOI, NEW DELHI: A CASE STUDY. International Journal of Research in Engineering and Technology 07(08):49-60. DOI: 10.15623/ijret.2018.0708006.

- Abd Nasier, Mohammad, and Khalid Adel Abdulrazzaq, 2021. Conventional Water Treatment Plant, Principles, and Important Factors Influence on the Efficiency, Design Engineering 16009-27.

- Bârjoveanu, George, Carmen Teodosiu, Andreea Florina Gîlcă, Ioana Roman, and Silvia Fiore. 2019. Environmental Performance Evaluation of a Drinking Water Treatment Plant: A Life Cycle Assessment Perspective, Environmental Engineering and Management Journal 18(2):513-22. DOI: 10.30638/eemj.2019.048.

- Chang, E. E., Peng Chi Chiang, Shu Mei Huang, and Yi Li Lin. 2007. Development and Implementation of Performance Evaluation System for a Water Treatment Plant: Case Study of Taipei Water Treatment Plant, Practice Periodical of Hazardous, Toxic, and Radioactive Waste Management 11(1):36-47. DOI: 10.1061/(ASCE)1090025X(2007)11:1(36).

- $\quad$ Choi, S., Yun, Z., Yoon, J., Kim, J., Hong, S., and Lee, Y., 2002. Performance evaluation program of water treatment plant in Korea. Water Science and Technology: Water Supply, 2(5-6), 143-148.

- García-Ávila, Fernando, César Zhindón-Arévalo, Robert Álvarez- Ochoa, Silvana Donoso-Moscoso, María D. Tonon-Ordoñez, and Lisveth Flores del Pino, 2020. Optimization of Water Use in a Rapid Filtration System: A Case Study, Water-Energy Nexus 3:1-10. DOI: 10.1016/j.wen.2020.03.005.

- Hassan, Fikrat M., and Ansam R. Mahmood, 2018. Evaluate the Efficiency of Drinking Water Treatment Plants in Baghdad City - Iraq, Journal of Applied \& Environmental Microbiology 6(1):1-9. DOI: 10.12691/jaem-6-1-1.

- Issa, Hayder, 2017. Evaluation of Water Quality and Performance for a Water Treatment Plant: Khanaqin City as a Case Study, Journal of Garmian University 3 (Khanaqine Conference):802-21. DOI: 10.24271/garmian.64.

- Kiggundu, Nicholas, Sam Cherotich, Noble Banadda, Isa Kabenge, and David Ogaram, 2016. Impact of Daily and Seasonal Variation of Raw Water Quality on Treatability: A Case of Gaba Complex, Global Journal of Engineering Science and Research Management 3(2):20-31.

- $\quad$ Mahmoud, H. M., Mohamed, E. A., Khalil, M. H., and Mahgoub, M. S., 2016. Comprehensive performance assessment of the potable water treatment plants in El 
Fayoum governorate, Egypt, Research Journal of Pharmaceutical Biological and Chemical Sciences, 7(5), 2189-2213.

- $\quad$ Ojok, Walter, John Wasswa, and Emmanuel Ntambi, 2017. Assessment of Seasonal Variation in Water Quality in River Rwizi Using Multivariate Statistical Techniques, Mbarara Municipality, Uganda, Journal of Water Resource and Protection 09(01):83-97. DOI: 10.4236/jwarp.2017.91007.

- Omran, Abdelnaser, 2011. Factors Influencing Water Treatment Management Performance in Malaysia: A Case Study in Pulau Pinang, Annals of Faculty Engineering Hunedoara-International Journal of Engineering 10(1):53-62.

- Mahmood, Rand Shakir, and Nawar O. A. Al-Musawi, 2020. Evaluating Electrocoagulation Process for Water Treatment Efficiency Using Response Surface Methodology, Journal of Engineering 26(9):11-23. DOI: 10.31026/j.eng.2020.09.02. 